\title{
Endoscopic sphincterotomy for common bile duct calculi in patients with gall bladder in situ considered unfit for surgery
}

\author{
B R DAVIDSON, J P NEOPTOLEMOS, AND D L CARR-LOCKE
}

From the Leicester Royal Infirmary, Leicester

SUMMARY Endoscopic sphincterotomy (ES) was attempted in 106 patients with common bile duct (CBD) calculi and gall bladders present, who were considered unfit for surgery on the grounds of age and frailty alone $(35 \%)$ and/or the presence of major medical problems $(65 \%)$. Endoscopic sphincterotomy was successful in 105 patients $(99 \%)$. Early ES related complications occurred in 21 patients $(19 \cdot 8 \%)$. Twelve hospital deaths occurred $(11 \cdot 3 \%)$, although this was due to biliary causes in only five $(4.7 \%)$ and one of these was moribund on admission. Complications were more frequent in those in whom initial ES did not clear the common bile duct $(30 \cdot 4 \%)$ compared with those in whom this was $(11 \cdot 7 \% ; p=0 \cdot 0164)$. The mortality was also greater in patients in whom there was no ERCP proof of CBD clearance $(p=0 \cdot 01)$ unless operated upon. Twelve patients developed gall bladder complications $(11 \cdot 3 \%)$ including five with empyema $(4 \cdot 7 \%)$. Analysis of clinical, haematological, and biochemical factors together with ERCP findings showed that the only factor which had any value in predicting gall bladder complications was pre-existing cholangitis. The present series was compared with another using ES as a definitive procedure, and with a surgical series. Although there were significant differences in outcome, differences with respect to medical risk factors and the incidence of complications of CBD stones (jaundice, cholangitis, and acute pancreatitis) were striking. Further analysis of these factors may allow a clearer definition of patients most likely to benefit from either ES or surgery.

Endoscopic sphincterotomy (ES) is a safe and effective method of managing common bile duct (CBD) calculi. From major centres clearance of the common bile duct is achieved in greater than $85 \%$ with an early complication rate of $10 \%$ and a mortality rate of less than $2 \% .^{1-4}$ The established role of ES for retained stones postcholecystectomy has been extended in recent years to the management of the early retained stones post cholecystectomy in patients with T-tube in situ,,$^{50}$ and the management of acute cholangitis. ${ }^{7}$ The role of ES for the removal of CBD calculi before cholecystectomy ${ }^{\times}$and in acute biliary pancreatitis ${ }^{9}$ remains under evaluation.

Many patients with gall bladder and CBD calculi

Address for correspondence: Mr J P Neoptolemos. FRCS, University Department of Surgery, Dudley Road Hospital, Birmingham B18 7QH.

Received for publication 3 August 1987. are elderly and often have major medical problems making them unsuitable candidates for surgery. In these patients ES may be used as a definitive procedure with the gall bladder being left in situ but significant complications may develop as a result of remaining gall bladder stones. A method of predicting those patients at a high risk of developing complications would be of value. Moreover a clearer definition is required of those patients with CBD stones who are indeed most likely to benefit from treatment by ES alone as compared with surgery alone.

This study represents our initial attempts to examine these problems and includes a comparison with two other studies of patients with CBD calculi in which sufficient information was available to allow statistical analysis. 


\section{Methods}

\section{PATIENTS}

Between August 1978 and December 1985106 patients from our local referral population with intact gall bladders who were considered at high risk for surgery on the grounds of age and/or associated medical problems had ES for CBD calculi with the intention of not proceeding to elective cholecystectomy. Patients referred from outside the Leicester area were excluded. Short and long term outcome was analysed together with various clinical and laboratory variables and the findings at ERCP in an attempt to predict which patients might develop significant complications of gall bladder disease. A comparison was then carried out between this group of patients and another undergoing ES as a definitive procedure $^{10}$ and a surgical series ${ }^{8}$ with respect to factors potentially important in the prediction of outcome.

\section{EN DOSCOPIC SPHINCTEROTOMY}

Diagnosis of CBD calculi was by ERCP in all cases. This was carried out using pharyngeal topical anaesthesia and intravenous sedation. All patients received prophylactic antibiotics before ES. Stone extraction after sphincterotomy was carried out as previously described"12 using Fujinon DUO-X and DUO-XL side viewing duodenoscopes and a Classen-Demling sphincterotome with an Erbotom T175D diathermy unit. Basket and/or balloon extraction was used in an attempt to clear the CBD in all cases (Olympus FG18Q dormia basket, Medi-Tech OB/5/2/200 balloon, KeyMed Ltd, Southend, Essex). In selected patients where removal of CBD calculi proved impossible a nasobiliary catheter was inserted at the time of ES and dissolution therapy was attempted by instilling mono-octanoin (Moctanin $\mathrm{T}^{\mathrm{m}}$, Capital City Products Company, Columbus, Ohio, USA) into the CBD through the catheter at $2-3 \mathrm{ml} / \mathrm{h}$.

Of the 106 patients 40 were male and 66 female with a median age of 79 years (range 47-92). Forty five patients $(42 \%)$ were 80 years or over. Presentation was pain and jaundice in 80 cases $(75.5 \%)$, pain alone in $19(18 \%)$, and jaundice alone in seven $(6 \cdot 5 \%)$. Twenty nine patients $(27 \%)$ had acute cholangitis on admission and 19 cases had acute pancreatitis $(18 \%)$. The diagnosis of acute cholangitis was based on the findings of a temperature of greater than $38^{\circ} \mathrm{C}$ with a history of rigors, clinically apparent jaundice and upper abdominal pain or tenderness. The diagnosis of acute pancreatitis was based on a serum amylase value of greater than $1000 \mathrm{IU} / \mathrm{l}$ with a compatible clinical picture.
Thirty seven patients were selected for ES as a definitive procedure on the grounds of age and frailty alone $(35 \%)$. The median age in this group was 80 years (range 61-92). Sixty nine patients were selected on the grounds of major medical problems $(65 \%)$. The median age of this group was 76 years (range $47-88), 38 \%$ of whom were 80 years or over. The age distribution of the two groups is shown in Figure 1 and the major medical problems in Table 1. A combination of major medical problems was present in 15 patients. Additional medical problems not considered to be major were present in 16 patients; these were peptic ulceration in eight, a history of malignant disease in four, chronic pancreatitis in three and chronic osteomyelitis in one.

\section{STATISTICAL ANALYSIS}

Continuous variables were analysed using the Mann Whitney $U$ test (Minitab computer package) and discrete variables were analysed using $\mathrm{X}^{2}$ test and $\mathrm{X}^{2}$ test with Yates correction for small expected numbers.

\section{Results}

Endoscopic sphincterotomy (ES) was successfully carried out in all but one of the 106 patients (Fig. 2). The failure was an 84 year old lady with severe angina

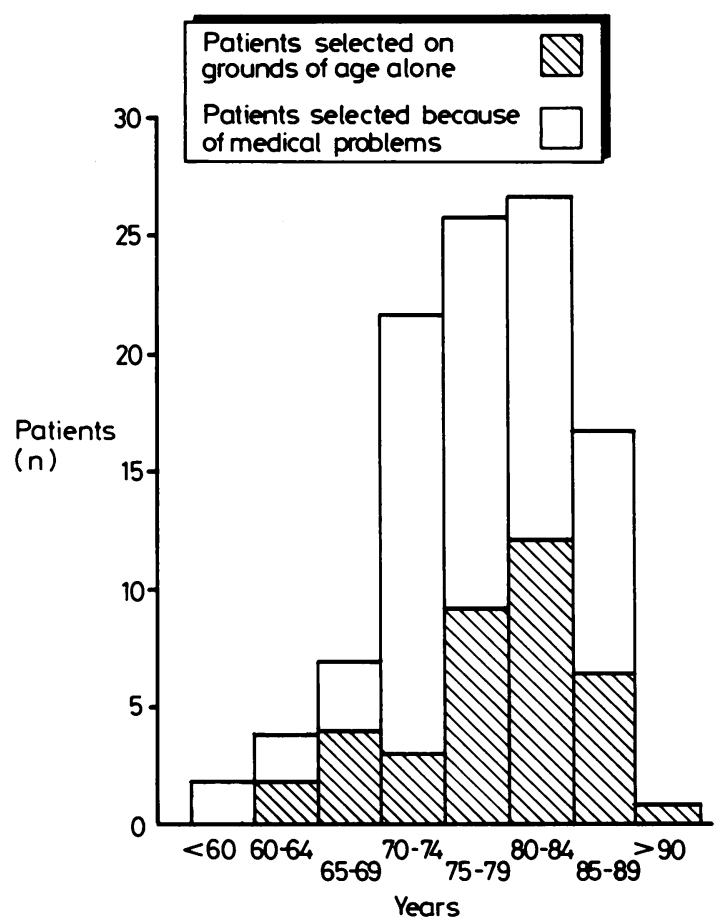

Fig. 1 Age group of patients undergoing ES. 
Table 1 Medical risk factors in the 69 patients selected for ES principally on medical grounds

$\begin{array}{lr}\begin{array}{l}\text { Cardiovascular } \\ \text { (History of MI, severe angina, congestive cardiac failure }\end{array} & 46 \\ \quad \text { or hypertension) } & 9 \\ \text { Diabetes mellitus } & 8 \\ \text { Chronic obstructive airways disease } & 6 \\ \text { Previous cerebrovascular accident } & 4 \\ \text { Severe phychiatric disorders } & 3 \\ \text { Morbid obesity } & 3 \\ \text { Haemolytic anacmias } & 2 \\ \text { Hypothyroidism } & 2 \\ \text { Previous pulmonary cmbolism } & 1 \\ \text { Lobar pneumonia } & 1 \\ \text { Multiple sclerosis } & 1 \\ \text { Polymyalgia rheumatica } & \end{array}$

who died from acute haemorrhagic pancreatitis after a needle knife choledochoduodenostomy for impacted stones at the ampulla of Vater. Seven patients (aged 72-86 years) had successful ES but failure to remove large CBD calculi. One of these
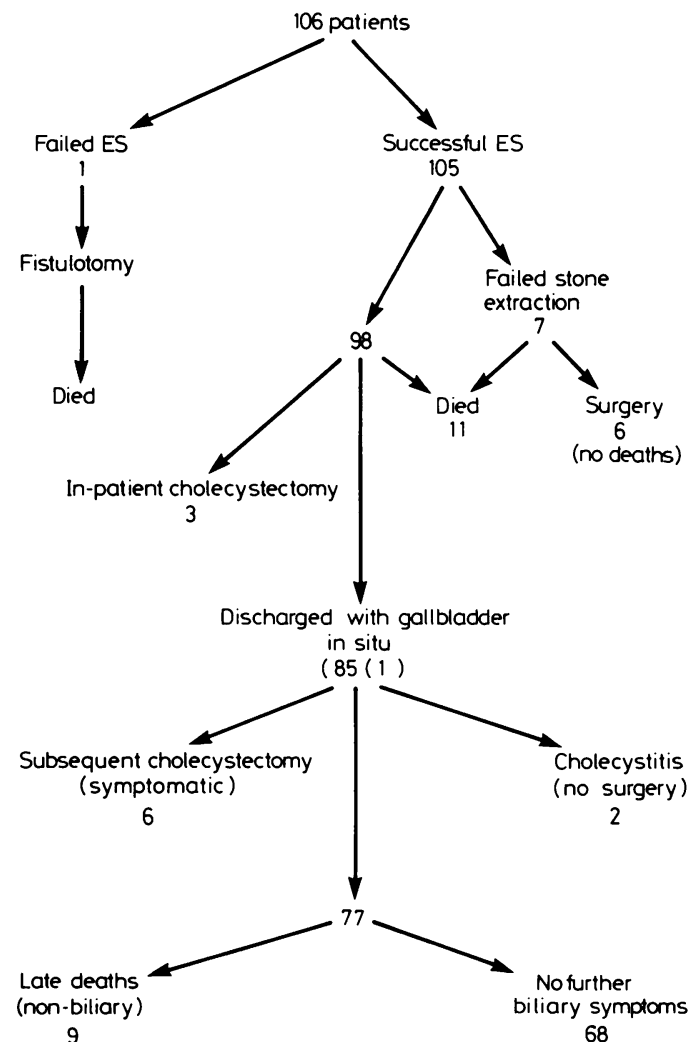

* One patient had percutaneous aspiration of gall bladder empyema Fig. 2 Outcome of patients undergoing ES for CBD stones.
Table 2 Details of all inpatient deaths $(n=12)$

\begin{tabular}{|c|c|c|c|c|}
\hline Age & Sex & Medical problems & $\begin{array}{l}\text { Retained } \\
\text { CBD stones* }\end{array}$ & * Cause of death \\
\hline \multicolumn{5}{|c|}{ Deaths directly related to ES } \\
\hline 84 & $\mathrm{~F}$ & Angina, CCF & Yes & Acute pancreatitis \\
\hline 85 & $\mathrm{~F}$ & Hypertension & Yes & Septicaemia \\
\hline 76 & M & Nil major & Yes (A) & $\begin{array}{l}\text { Septicaemia/empyema } \\
\text { of the gall bladder }\end{array}$ \\
\hline 84 & M & Hypertension & Yes & $\begin{array}{l}\text { Septicaemia (awaiting } \\
\text { surgery) }\end{array}$ \\
\hline 71 & $\mathrm{~F}$ & $\begin{array}{l}\text { Angina, CCF, } \\
\text { Diabetes, Renal } \\
\text { Failure }{ }^{\dagger}\end{array}$ & $\mathrm{Yes}(\mathrm{A})$ & $\begin{array}{l}\text { Septicaemia/liver } \\
\text { abscess/multisystem } \\
\text { failure }\end{array}$ \\
\hline \multicolumn{5}{|c|}{ Deaths remotely related to ES } \\
\hline 68 & M & $\begin{array}{l}\text { Angina, CCF, } \\
\text { Hypertension }\end{array}$ & $?$ & $\begin{array}{l}\text { Cardiac and respiratory } \\
\text { failure }\end{array}$ \\
\hline 86 & $\mathbf{F}$ & Nil major & No & Myocardial infarct \\
\hline 84 & $\mathbf{M}$ & CVA & No & Aspiration pneumonia \\
\hline 81 & $\mathrm{~F}$ & CCF & No & $\begin{array}{l}\text { Haematemesis from } \\
\text { gastric erosions }\end{array}$ \\
\hline 89 & M & CCF & No & $\begin{array}{l}\text { Pancreatic carcinoma } \ddagger / \\
\text { septicaemia/empyema } \\
\text { of gall bladder }\end{array}$ \\
\hline 65 & M & CCF, COAD & No & Bronchial carcinoma $\ddagger$ \\
\hline 85 & $\mathrm{~F}$ & Nil major & No & Ovarian carcinoma $\ddagger$ \\
\hline
\end{tabular}

*Status of CBD as shown by ERCP or autopsy (A): tmoribund on admission; ¥malignant disease diagnosed at autopsy;

$\mathrm{F} / \mathrm{M}=$ female/male $; \mathrm{CCF}=$ congestive cardiac failure;

$\mathrm{CVA}=$ cerebrovascular accident $; \mathrm{COAD}=$ chronic obstructive airways disease.

patients aged 85 years was considered unfit for surgery and died from cholangitis. Six patients were referred for surgery and had cholecystectomy and CBD clearance carried out. Despite four having major medical problems all survived although two patients developed wound and chest infections, one patient developed septicaemic shock which responded to fluids and antibiotics, and another had a wound infection.

Of the remaining 98 patients confirmation of CBD clearance was obtained in 79 patients $(81 \%)$. Complete clearance was determined at the time of initial ERCP in 60 cases. Seventeen other patients had confirmation at a repeat ERCP and two additional patients had two further ERCP's. Nine patients required a further ES to allow CBD clearance and two patients had two further ES's. The remaining 19 patients $(19.4 \%)$ were felt to have had a sphincterotomy adequate to allow spontaneous clearance of the CBD. Ten of these 98 patients died and details are given in Table 2 .

DISSOLUTION THERAPY

Three patients had attempted dissolution of CBD stones and this was successful in two. The one patient who failed dissolution had an endoprosthesis inserted and remains well two years later. 
OUTCOME OF PATIENTS PRESENTING WITH

ACUTE CHOLANGITIS AND PANCREATITIS

Of the 29 patients presenting with cholangitis four had a further episode of cholangitis post-ES. Four of the group developed an empyema of the gall bladder one of whom died (vide infra). A further death was from cholangitis and liver abscess in a patient with failed CBD clearance. Three patients in this group had retained CBD stones post-ES and underwent surgery as previously mentioned. The overall mortality of patients presenting with cholangitis was $6.9 \%$.

All 19 patients with acute pancreatitis had successful ES and stone extraction with only one ES related complication in a patient with concomitant cholangitis (included in the above).

EMPYEMA OF THE GALL BLADDER

Five of the 106 patients with CBD stones developed an empyema of the gall bladder after ES $(4.7 \%)$ and two had this before ES. One patient had had cholecystostomy for empyema of the gall bladder and subsequently underwent elective cholecystectomy post-ES. The other patient had an empyema of the gall bladder and choledochoduodenal fistula at the time of ES and underwent an emergency cholecystectomy. Four of the five patients who formed an empyema of the gall bladder after ES, had presented with cholangitis $(14 \%)(p=0.036)$. One of the five patients responded to ultrasound directed aspiration of the gall bladder. Two other patients had urgent cholecystectomy with no complications. In the remaining two patients with empyema of the gall bladder, the diagnosis was only made at autopsy. One of these patients died from septicaemia shortly after readmission to hospital and was found to have CBD stones as well as an empyema. The other patient had carcinoma of pancreas and liver secondaries in addition to the empyema. Overall two of the seven patients with empyema of the gall bladder died $(29 \%)$.

\section{OVERALL INPATIENT COMPLICATIONS AND} MORTALITY

Twenty one of the patients had early complications related to attempted ES (19.8\%) (Table 3). Nine of these patients $(42.9 \%)$ had more than one complication. Twelve of the 21 patients $(57 \cdot 1 \%)$ had retained CBD stones; six of the 12 patients underwent further ES with complete clearance, four had surgery with a successful outcome, one died after a needle fistulotomy, and another died having been considered unfit for surgery. In total 12 patients $(11.3 \%)$ died during their hospital admission although this was from biliary causes - all associated with retained stones - in only five $(4.7 \%)$ and one of these was
Table 3 Early complications related to attempted ES in all 106 patients (1-30 days)

\begin{tabular}{lcr}
\hline Complication & Number \\
\hline Acute cholangitis & $11\left(4^{*}\right)$ & $10 \cdot 4 \%$ \\
Post-ES bleeding & 7 & $6 \cdot 6 \%$ \\
Septicaemia & 5 & $4 \cdot 7 \%$ \\
Empyema of gall bladder & $5\left(4^{*}\right)$ & $4 \cdot 7 \%$ \\
Acute pancreatitis & 2 & $1 \cdot 9 \%$ \\
Patients with complications $(\mathrm{n})$ & 21 & $19 \cdot 6 \%$ \\
Deaths $(\mathrm{n})$ & 5 & $4 \cdot 7 \%$ \\
\hline
\end{tabular}

*Number with pre-existing cholangitis.

moribund on admission. Excluding patients who died of malignant disease there was a higher mortality in the group who did not have confirmation of CBD clearance by ERCP $(6 / 27$ or $22 \%)$ compared to those who did $(3 / 79$ or $4 \%)(p=0 \cdot 01)$. Furthermore in patients without ERCP proof of CBD stone clearance, five of the six deaths were related to retained CBD stones, whereas the three non-cancer related deaths in patients who did have CBD clearance confirmed were from non-biliary causes. Complications after ES were greater in patients in whom initial ES did not result in CBD clearance $(14 / 46$ or $30 \%)$ compared to those in whom this was $(7 / 60$ or $12 \%)$ $(p=0.0164)$.

\section{LONGTERM OUTCOME}

Eighty five patients with gall bladder in situ were discharged from hospital after ES and were followed up for 1-8 years (mean 29.6 months). Eight patients developed symptoms referrable to the gall bladder $(9 \cdot 4 \%)$ of whom six had cholecystectomy. Two patients represented with cholangitis and were found to have retained CBD stones at operation. Neither patient had had confirmation of CBD clearance at the time of ES. Surgery was undertaken in two patients because of repeated episodes of biliary colic and in one because of acute cholecystitis. An elective cholecystectomy was performed in another patient who had had cholecystostomy for empyema of the gall bladder before ES.

None of the 79 patients who had had confirmation of CBD clearance subsequently presented with retained or recurrent CBD calculi, although two of these patients had had an episode of cholecystitis but were not considered for surgery. Nine patients died from unrelated causes: myocardial infarction in four cases, pneumonia in three instances and pulmonary tuberculosis and pulmonary embolism in one each. Sixty eight patients did not report any further biliary tract symptoms. None of the 19 patients who presented with acute pancreatitis have had a further episode of pancreatitis during a mean follow up period of 39 months. 
PREDICTION OF POST-ES GALL BLADDER COMPLICATIONS

None of the factors analysed in an attempt to define at the time of admission the group of patients who might subsequently develop significant gall bladder pathology (empyema, acute cholecystitis or recurrent biliary colic) were found to be significant (Table 4).

COMPARISON WITH ANOTHER SERIES OF

DEFINITIVE ES AND A SURGICAL. SERIES

Table 5 shows a statistical comparison of the presenting features and mortality for the present group of patients together with those of a Manchester series of definitive ES ${ }^{\prime \prime \prime}$ and a Leicester series of surgery for CBD stones. ${ }^{\star}$

\section{Discussion}

Cholecystectomy is an operative procedure with a low mortality rate of $1 \% .^{12-16}$ In contrast when CBD exploration is required the risk is greatly increased, esecially in elderly patients in whom mortality rates of $9-30 \%$ have been reported. ${ }^{17 \mathrm{I}}$ Endoscopic sphincterotomy with a mortality of less than $2 \%$ has obvious advantages for managing CBD calculi in elderly patients if cholecystectomy is avoided. ${ }^{14} 21$ Previously published series have suggested that approximately $10 \%$ of patients eventually require

Table 4 Comparison of patients developing and those not developing significant gall bladder complications

\begin{tabular}{|c|c|c|}
\hline & $\begin{array}{l}\text { Complications }(n=12) \\
\text { (empyema, cholecystitis } \\
\text { or biliary colic) }\end{array}$ & $\begin{array}{l}\text { No } \\
\text { Complications } \\
(n=86)\end{array}$ \\
\hline Age (years) & $75 \cdot 5(58-89)$ & $79(47-92)$ \\
\hline Sex male/female & $7 / 5$ & $3(0 / 56$ \\
\hline Acute pancreatitis & $1(8 \%)$ & $18(21 \%)$ \\
\hline Acute cholangitis & $5(42 \%)$ & $21(24 \%)$ \\
\hline White cell count & $9 \cdot 6(4 \cdot 7-20 \cdot 6)$ & $8 \cdot 8(1 \cdot 2-40)$ \\
\hline Bilirubin $(\mu \mathrm{mol} / 1)$ & $103(14-425)$ & $71(5-491)$ \\
\hline $\begin{array}{l}\text { Alkaline phosphatase } \\
\text { (IU/l) }\end{array}$ & $331(89-834)$ & $456(85-3047)$ \\
\hline $\begin{array}{l}\text { Gamma glutamyl } \\
\text { transpeptidase (IU/I) }\end{array}$ & $283(47-734)$ & $313(22-1164)$ \\
\hline $\begin{array}{l}\text { Alanine transaminase } \\
\text { (IU/I) }\end{array}$ & $146(17-313)$ & $114(10-1114)$ \\
\hline \multicolumn{3}{|l|}{ ERCP findings } \\
\hline CBD diameter & $12 \cdot 5(8-20)$ & $13(5-26)$ \\
\hline Gall bladder filling & $6(50 \%)$ & $46(53 \%)$ \\
\hline \multicolumn{3}{|l|}{ Gall bladder } \\
\hline No filling & $6(50 \%)$ & $40(47 \%)$ \\
\hline Filling No stones & $1 / 6(17 \%)$ & $7 / 46(15 \%)$ \\
\hline Single stones & $1 / 6(17 \%)$ & $6 / 46(13 \%)$ \\
\hline Multiple stones & $4 / 6(67 \%)$ & $33 / 46(72 \%)$ \\
\hline
\end{tabular}

Median values (range). None of these values was significantly different. cholecystectomy ${ }^{211}$ and the incidence of $7 \%$ in the present series is in accordance with this.

Although ES was achieved in all but one patient $(99 \%)$ confirmation of CBD clearance by ERCP was obtained in only $81 \%$. This is somewhat lower than that in previously reported series from Leicester ${ }^{7 \times 211}$ and other centres. ${ }^{2}{ }^{3}$ There are two possible explanations for this difference. Firstly, in some series CBD clearance may be assumed when ES is followed by resolution of symptoms rather than being confirmed by repeat ERCP or nasobiliary cholangiography. Secondly, this figure may reflect a reluctance to have ERCP repeated in elderly and frail patients, often with major medical problems, when symptoms have subsided.

The overall hospital mortality was significantly higher in patients having either failed stone extraction or no confirmation of CBD clearance compared with those patients having confirmation of CBD clearance. Complications after ES were also increased if CBD clearance was not achieved at initial ERCP and ES. All five deaths caused by post-ES complications were associated with retained stones. The remaining seven deaths were because of malignancy or other intercurrent medical problems; six of these patients had successful stone clearance and in one cases this was uncertain. Surgery should be seriously reconsidered at an early stage for patients with incomplete stone clearance - indeed six patients were operated on without mortality - but it may not be feasible. Endoscopic insertion of a nasobiliary catheter followed by dissolution therapy,," or placement of a biliary endoprosthesis:2 may, however, improve the prognosis of this group of patients.

Seven patients $(6 \cdot 6 \%)$ had an empyema of the gall bladder and in five cases this followed ES which was done in the presence of acute cholangitis in four. As preoperative ES results in a higher incidence of positive gall bladder bile cultures, ${ }^{x}$ it seems likely that ES in the presence of marked biliary tract sepsis predisposes to the development of empyema of the gall bladder. The mortality rate for patients with empyema of the gall bladder was 29\% in this series. Previously mortality rates of $15-25 \%$ have been reported and has been highest in those in whom treatment was delayed.".3 The recent introduction of ultrasound directed percutaneous gall bladder catheterisation, as used in one case in this series, may improve the prognosis for high surgical risk $^{24}{ }^{25}$ patients. Dissolution therapy via the catheter may avoid the need for subsequent cholecystectomy. ${ }^{2 h}$

After an initial attack of acute biliary pancreatitis early cholecystectomy is usually recommended to prevent further episodes. ${ }^{27-29}$ None of the patients who presented with acute pancreatitis and in whom the gall bladder remains in situ have had a further 
Table 5 Comparison of the present and Manchester ES (10) series with a Leicester surgical study (8)

\begin{tabular}{|c|c|c|c|c|c|c|c|c|c|}
\hline & \multicolumn{2}{|c|}{$\begin{array}{l}\text { Series A present ES } \\
\text { study }(n=106)\end{array}$} & \multicolumn{2}{|c|}{$\begin{array}{l}\text { Series B Manchester } \\
\text { ES study }(n=81)\end{array}$} & \multicolumn{2}{|c|}{$\begin{array}{l}\text { Series C Surgical } \\
\text { study }(n=59)\end{array}$} & \multicolumn{3}{|c|}{ pvalues } \\
\hline & $n$ & $(\%)$ & $n$ & $(\%)$ & $n$ & $(\%)$ & $A \vee B$ & $A \vee C$ & $B \vee C$ \\
\hline Jaundice & 87 & $(82)$ & 56 & (69) & 52 & $(88)$ & $0 \cdot 036$ & NS & 0.008 \\
\hline Acute cholangitis & 29 & (27) & 15 & (19) & 9 & (15) & NS & NS & NS \\
\hline Acute pancreatitis & 19 & (18) & 5 & (6) & 1 & (2) & 0.018 & $0 \cdot 005$ & NS \\
\hline Age $>60$ years & 105 & (99) & 74 & (91) & 30 & (51) & NS & $0 \cdot 001$ & 0.001 \\
\hline Major medical problems & 69 & $(65)$ & 32 & $(40)$ & 15 & $(25)$ & 0.001 & $0 \cdot 001$ & NS \\
\hline Mortality & 9/103* & $(8 \cdot 7)$ & 1 & $(1.2)$ & 1 & $(1.7)$ & 0.038 & NS & NS \\
\hline
\end{tabular}

${ }^{*}$ Three patients with previously undiagnosed carcinoma not included; NS=not significant.

episode. It seems likely, therefore, that ES alone has a role in elderly patients with acute biliary pancreatitis.

Prediction of gall bladder complications after ES would be valuable in allowing early therapeutic radiological intervention or reconsideration of surgical options. Only the presence of cholangitis indicated an increased risk of gall bladder complications. The presence or absence of gall bladder filling on ERCP as suggested by Cotton ${ }^{310}$ has not been found to be a useful indicator.

The comparative study with the Manchester ES series $^{11}$ and the surgical series ${ }^{8}$ has provided some insight into the factors which are responsible for the morbidity and mortality in patients presenting with CBD stones. Their outcome will be dependent on the techniques used, the skill of the endoscopist and the type of patient involved. In comparing the present series with that from Manchester (Table 5) it has been shown that despite similar age ranges in both groups being managed by ES the mortality was significantly different. The contrast between these series with respect to the incidence of jaundice, acute pancreatitis and intercurrent medical problems was, however, even more striking. The mortality of a surgical series from Leicester was less than that of the present series of patients undergoing ES but they were younger and had fewer major medical problems. Furthermore the mortality in the Manchester ES series and the Leicester surgical series was not significantly different, nor was their incidence of major medical problems. Although the patients in the Manchester series were older the Leicester surgical patients more commonly presented with jaundice.

Cotton has drawn attention to the difficulties faced in attempting to draw conclusions from the results of surgical and ES series because of the different make up in these groups. ${ }^{30}$ Adverse risk factors in biliary tract disease have been derived from surgical series largely composed of patients with malignancy. ${ }^{31-33}$ The use of medical risk factors as used here has been shown to be of importance in determining mortality from acute cholangitis as a result of choledocholithiasis. ' Determination of specific risk factors which can be applied to all patients with CBD stones ought to be a major goal now as a means of furthering progress in defining the optimum management of these patients.

We are extremely grateful to all the surgeons in Leicestershire for allowing their patients to be included in this study. The critical remarks of $\mathrm{Mr}$ D F L Watkin, Consultant Surgeon, are acknowledged. Finally we thank Denise Huckerby for secretarial assistance.

\section{References}

1 Safrany L. Endoscopic treatment of biliary tract disease. Lancet 1978; ii: 983-5.

2 Escourrou J, Cordova JA, Lazorthes F, et al. Early and late complications after endoscopic sphincterotomy for biliary lithiasis, with and without the gallbladder in situ. Gut 1984; 25: 598-602.

3 Cotton PB, Vallon AG. British experience with duodenoscopic sphincterotomy for removal of common bile duct stones. Br J Surg 1981; 68: 373-5.

4 Leese T, Neoptolemos JP, Carr-Locke D. Successes, failures, early complications and their management following endoscopic sphincterotomy. Results in 394 consecutive patients from a single centre. Br J Surg 1985; 72: 215-9.

5 Ghazi A, Beaton H. Early endoscopic sphincterotomy for extraction of residual stones of the common bile duct. Surg Gynecol Obstet 1984; 159: 45-6.

6 O'Doherty DP, Neoptolemos JP, Carr-Locke D. Endoscopic sphincterotomy for retained common bile duct stones in patients with T-tube in situ in the early post operative period. Br J Surg 1986; 73: 454-6.

7 Leese T, Neoptolemos JP, Baker AR, Carr-Locke DL. Management of acute cholangitis and the impact of endoscopic sphincterotomy. BrJ Surg 1986; 73: 988-92.

8 Neoptolemos JP, Carr-Locke DL, Fossard DP. Results of a prospective study of pre-operative endoscopic sphincterotomy versus surgery alone for common bile ducts stones. Br Med J 1987; 294: 470-4. 
9 Neoptolemos JP, London N, Slater ND, Carr-Locke DL, Fossard DP, Moossa AR. A prospective study of ERCP and endoscopic sphincterotomy in the diagnosis and treatment of gallstone acute pancreatitis. Arch Surg 1986; 121: 697-702.

10 Martin DF, Tweedle DE. Endoscopic management of common duct stones without cholecystectomy. BrJ Surg 1987; 74: 209-11.

11 Kawai K, Akasaka Y, Murokami M, et al. Endoscopic sphincterotomy of the ampulla of Vater. Gastrointest Endosc 1974; 20: 148-51.

12 Classen M, Safrany L. Endoscopic papillotomy and removal of gallstones. $\mathrm{Br}$ Med J 1975; 4: 371-4.

13 Doyle PJ, Ward McQuaid JN, McEwan Smith A. The value of routine pre-operative cholangiography - A report of 4000 cholecystectomies. Br J Surg 1982; 69: 617-9.

14 Cranley B, Cogan H. Exploration of the common bile duct - the relevance of the clinical picture and the importance of peroperative cholangiography. Br J Surg 1980; 67: 869-72.

15 Kakos GS, Tompkins RK, Turnipseed W, et al. Operative cholangiography during routine cholecystectomy. Arch Surg 1972; 104: 484-7.

16 Seitzer MH, Sleiger E, Rosato FE. Mortality following cholecystectomy. Surg Gynecol Obstet 1970; 130: 64-6.

17 Vellacott KD, Powell PH. Exploration of the common bile duct: A comparative study. Br J Surg 1979; 66: 389-91.

18 Roukema JA, Carol EJ, Lieu F, Jakimowicz JJ. A retrospective study of surgical common bile duct exploration: ten years experience. Netherlands J Surg 1986; 38: 11-4.

19 Mee AS, Vallon AG, Croker JR, et al. Non-operative removal of bile duct stones by duodenoscopic sphincterotomy in the elderly. Br Med J 1981; 283: 521-3.

20. Cotton PB, Vallon AG. Duodenoscopic sphincterotomy for removal of bile duct stones in patients with gallbladders. Surgery 1982; 91: 628-30.
21 Neoptolemos JP, Hoffman AF, Moossa AR. The chemical treatment of stones in the biliary tree. BrJ Surg 1986; 73: 515-24.

22 Carr-Locke DL, Cotton PB. Biliary tract and pancreas. Br Med Bull 1986; 42: 257-64.

23 Fry DE, Cox RA, Harbrecht PJ. Empyema of the gallbladder: A comparison in the natural history of acute cholecystitis. Am J Surg 1981; 141: 366-9.

24 Radder RW. Ultrasonically guided percutaneous catheter drainage for gallbladder empyema. Diagn Imaging 1980; 49: 330-3.

25 Van Sonnenberg E, Wittich GR, Casola G, et al. Diagnostic and therapeutic percutaneous gallbladder procedures. Radiology 1986; 160: $23-6$.

26 Allen MJ, Borody TJ, Bugliosi TF, et al. Rapid dissolution of gallstones by methyl tert-butyl ether. $N$ Engl J Med 1985; 312: 217-20.

27 Paloyan D, Simonowitz D, Skinner DB. The timing of biliary tract operations in patients with pancreatitis associated gallstones. Surg Gynecol Obstet 1975; 141: 737-9.

28 Elfstrom $\mathbf{J}$. The timing of cholecystectomy in patients with gallstone pancreatitis. Acta Chir Scand 1978; 144: 487-9().

29 Osborne DH, Imrie CW, Carter DC. Biliary surgery in the same admission for gallstone associated pancreatitis. Br J Surg 1981; 68: 758-61.

30 Cotton PB. Endoscopic management of bile duct stones: (Apples and oranges). Gut 1984; 25: 587-97.

31 Pitt HA, Cameron JL, Postier RG, Gaducz TR. Factors affecting mortality in biliary tract surgery. Am J Surg 1981; 141: 66-71.

32 Blamey SL, Fearon KCH, Gilmour WH, Osborne DH, Carter DC. Prediction of risk in biliary surgery. $\mathrm{Br} J$ Surg 1983; 70: 535-8.

33 Armstrong CP, Dixon JM. Taylor TV, Davies GC. Surgical experience of deeply jaundiced patients with bile duct obstruction. Br J Surg 1984; 71: 234-8. 